\title{
Um risco no céu: a vivência do espaço na formação do professor contemporâneo
}

Suca Mattos Mazzamati é artista plástica, arte-educadora, graduada em Licenciatura em desenho e plástica pela Fundação Armando Álvares Penteado, especialista em Arte, Educação e Tecnologias Contemporâneas pelo Instituto de Artes da Universidade de Brasília, assessora de arte do terceiro ao quinto ano da Escola Vera Cruz.

Contato: sucam@uol.com.br e www.suca.com.br

\section{Resumo}

Este artigo discute a importância da reflexão do professor sobre os conceitos de espaço e imagem e a possível interferência que isto possa ter na sua prática em sala de aula. Para tanto, são utilizadas como referência as obras de Flusser e Certeau. São também apresentados exemplos de como os professores podem vivenciar, através da arte, a experiência de transformação e ocupação dos espaços seja ele no papel, na argila ou em intervenções de grande porte como a sala de aula.

Palavras-chave: espaço; imagem; formação de professor; sala de aula; contemporaneidade; arte.

\section{Abstract}

The present article discusses the importance of the teacher's consideration on concepts of space and image and its possible interference in the practice during classroom activities.

For such purpose, the works of Flusser and Certeau are used as reference. Examples as how teachers may live the experience of transforming and occupying a space through art, whether on paper, on clay or in major interventions such as a classroom are also presented. Keywords: space; image; teacher's formation; classroom; contemporaneity; art. 
Pensar na influência que a apropriação espacial da sala de aula pode representar nas relações de ensino e aprendizagem é o tema deste artigo. Mais do que organizar o mobiliário: cadeiras, mesas, estantes e todos os materiais didáticos, que outras interferências espaciais podem influir na aprendizagem? Se o professor tem como foco um aluno com o conhecimento aprendido e construído, o que acontece entre o aluno e seu entorno até chegar a esta projeção? Se a figura imaginada ocupa o lugar principal, o espaço vivido até chegar a ela ou tem menos importância ou está a serviço desta mesma imagem, que é imaginada pelo professor, pela instituição escolar, pela sociedade.

\footnotetext{
A imagem que você tem em sua vida, como cidadão, como membro de uma família, inspira suas expectativas quando você pensa nas crianças e cria escolas para elas. Isto também se aplica à sociedade. A infância é reinventada por cada sociedade: cada sociedade pode criar a sua própria imagem do que são as crianças. A imagem é uma convenção cultural, e existem muitas imagens possíveis (Edwards; Gandini, 2002, p. 76).
}

Para o filósofo Vilém Flusser, "imagens são mediações entre o homem e o mundo" (2002, p. 9). Para ele, o que produz a imagem é a imaginação: "a capacidade de fazer e decifrar imagens" (op. cit.). 0 professor tem uma visão imaginada da transformação que pode oportunizar ao seu aluno. 0 que faz está em função dessa criação: "cada sociedade pode criar a sua própria imagem do que são as crianças" (Edwards; Gandini, 2002, p.76).

0 objetivo na educação é que o aluno aprenda. Como foco, esta aprendizagem deve conter o maior número de conteúdos previstos nas instituições de cada país. Mas, em vez de pensar como objetivo, pensemos sob a forma de imagens.

Acompanhem agora a criação dos seguintes quadros imaginários:

1. Em primeiro plano há um aluno sentado em sua cadeira atrás de uma mesa escolar. Do lado direito de quem olha tem uma janela, atrás dele outras mesas e cadeiras em fila. Dá para ver os outros alunos, mas estão desfocados. Do lado esquerdo mais mesas e cadeiras e mais alunos, bem no canto esquerdo uma porta. Há murais nesta parede da porta. 0 aluno é a figura principal e o fundo, a sala de aula. É o retrato de um aluno. Sua camisa é branca, tem as mãos sobre o seu caderno que está sobre a mesa. Ele sorri; 
2. De pé uma mulher está em frente a uma lousa. Sua mão está apoiada sobre uma mesa que está ao seu lado esquerdo de onde vem uma luz. Ela sorri. Há certa tensão em seu olhar. A lousa é verde.

Nestas duas imagens temos dois protagonistas, em uma 0 aluno e na outra a professora. São imagens em que a estrutura do quadro imaginado é determinada por uma figura central e um fundo que evidencia esta figura como foco principal de atenção. A imagem número um mostra um aluno sorridente. A sua mão sobre o caderno parece informar a satisfação que tem de estar naquele lugar. A situação exposta parece concretizar a imagem idealizada que o professor tem do aluno: um aluno que gosta de aprender e que aprenda. A imagem dos alunos ao fundo, apesar de não serem os atores principais, mostra que há muitos deles, muitos que gostam de aprender e que aprendem.

A imagem número dois pode nos levar a pensar, talvez imediatamente, na figura feminina da professora com a autoridade de quem tem o papel de ensinar. Está ao lado de sua mesa, com a mão esquerda apoiada nela, parecendo nos informar sobre certa necessidade de apoio e segurança. A lousa é verde e não tem nada escrito ou desenhado nela. A tensão gerada em seu rosto nos dá a ideia de um início de aula acrescido pelo inesperado, ela não sabe ao certo o que irá acontecer. Apoia-se no conhecido, mas sabe que o desconhecido está presente sempre. Pode também estar tensa por qualquer outro motivo.

Tomemos como terceiro exemplo o quadro de Manet, Le déjeuner sur l'herbe (0 almoço na relva), pintado em 1863 e reproduzido na imagem abaixo.

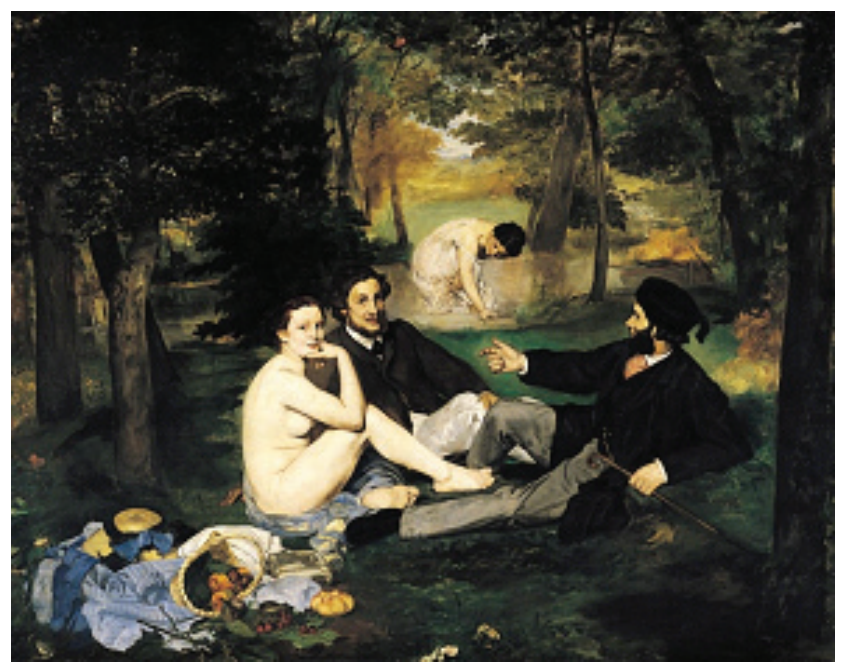

Imagem 1. MANET, Edouard. Le déjeuner sur l'herbe, óleo sobre tela, $208 \times 264,1863$, Museu D’Orsay, Paris. 
No quadro de Manet as figuras humanas protagonizam a cena em dois planos. Um mais ao fundo, com uma mulher, e outro à frente com três figuras principais. Estes focos criam ao olhar duas situações diversas ao mesmo tempo. Há também um ponto no infinito que faz o olhar ver longe. À esquerda, um caminho mais escuro e da mesma forma convidativo. Bem à direita o corte de um tronco de árvore parece dar o apoio a toda a construção da imagem. Tudo acontece em um lugar natural, com árvores, relva, riacho e uma luminosidade quase que real, unindo todos os elementos que estão dispostos no quadro. Há uma mulher nua que repousa entre dois homens vestidos que conversam entre si. A cor clara desta mulher em relação às vestes pretas dos homens chama a atenção tanto pelo fato de estar nua e quanto com relação à situação da mulher vestida ao fundo e que toca a água. Além das figuras humanas há uma cesta em primeiro plano com frutas e outros alimentos, e as roupas da modelo ao lado em tons de azul.

Poderíamos analisar muitas outras imagens, dentro e fora da do contexto de história da arte, no que diz respeito à questão fundo e figura e como estes focos se inter-relacionam, mas o que nos interessa é que todos os elementos de cada quadro analisado são importantes quando consideramos o espaço. Como afirma Flusser (2002, p. 9),

\footnotetext{
Imagens têm o propósito de representar o mundo. Mas, ao fazê-lo, interpõem-se entre o mundo e o homem. Seu propósito é serem mapas do mundo, mas passam a ser biombos. 0 homem, ao invés de se servir das imagens em função do mundo, passa a viver em função das imagens.
}

Agora vamos pensar que, como o avião que risca o céu, todo o trânsito que acontece entre os elementos da sala de aula provoca marcas, faz seu desenho no espaço. Certeau (1990, p. 201) afirma que "existe espaço sempre que se tomam em conta vetores de direção, quantidades de velocidade e a variável do tempo. 0 espaço é um cruzamento de móveis. É de certo modo animado pelo conjunto de movimentos que aí se desdobram". Assim, se entendermos o espaço como sendo todas as relações que acontecem dentro dele, não há protagonista e, sim, pontos de onde saem linhas de interação que se intercalam em cruzamentos conhecidos ou inteiramente novos. Neste sentido, Salles (2006, p. 26) defende que 


\begin{abstract}
consequente estabelecimento de critérios.
A interatividade é, portanto, uma das propriedades da rede indispensável para falarmos dos modos de desenvolvimento de um pensamento em criação...

É importante pensarmos no ato criador como um processo inferencial, no qual toda a ação, que dá forma ao novo sistema, está relacionada a outras ações de igual relevância, ao se pensar um processo como todo.
\end{abstract}

Mesmo que efêmera e modificada pela realização de nova atividade ou ação didática, estes atos deixam seu traço: é o desenhar do professor no espaço de seu ofício. A imagem de um espaço em constante mutação é o que queremos representar: "libertar-se dos cânones acadêmicos é importante para a orientação contemporânea, hoje desenho é linha, gesto e movimento que gera espaços em superfícies e no espaço físico e virtual" (lavelberg, 2006, p. 72).

Se a composição da sala de aula é sempre delimitada pelas cadeiras e mesas no mesmo lugar e a mesa do professor está à frente de seus alunos, em destaque, a análise que pode ser feita dessa imagem é a de que as relações que ali se constroem estão fixas. Ao pensar no espaço como um cenário para o desenrolar de uma cena, muitas vezes já apresentada, pode-se perder uma nova forma de participação que a contemporaneidade nos oferece: o lugar das relações e da investigação do conhecimento onde as partes se juntam formando conexões.

Nesse processo, mesmo que as transformações que ocorram nem sempre sejam visíveis pela característica de suas sutilezas, elas são percebidas no seu desenvolvimento. Outras vezes são abruptamente escancaradas pela produção e pelas opiniões críticas explicitadas pelos alunos. Como afirma Salles (2006, p. 26), "foge-se assim da busca pela origem da obra e relativiza-se a noção de conclusão. Cada versão contém, potencialmente, um objeto acabado e o objeto considerado final representa, de forma potencial, também, apenas um dos momentos do processo".

Se a consciência do espaço como lugar de relações estiver presente para os participantes desta aventura que é aprender, bastará para que a sala de aula contenha 
todos os elementos necessários para a criação de um intrincado movimento de vetores, e sua riqueza seja ampliada.

Tanto a sala de aula como o tempo cronológico da aula são fixos e próprios, são pré-combinados pela instituição escolar e não podem ser mudados. Aqui é a sala de arte, aqui é o $4^{\circ} \mathrm{B}$, aqui a biblioteca, e por aí vai. Por questão de organização, os lugares e o tempo são tão fixos como são o lugar das paredes, da porta e das janelas na escola.

Mas sabemos que, ao mesmo tempo, a sala de aula é o cruzamento de diferentes vertentes entre diferentes pontos que se proliferam e que também não são fixos. 0 foco na aprendizagem relacional não pode considerar apenas o binômio eu ensino, eu aprendo, centrado nos sujeitos. A criação de espaços, ou melhor, o seu desenho recriado sugere aos alunos experiências múltiplas e, principalmente, aguça a sua vontade de conhecer e investigar o mundo ao mesmo tempo em que é investigado. Como na pintura de Manet, toda a natureza e a luz representada têm o seu papel na transformação da situação, são também vetores a serem considerados, mas não estão em função da figura principal. Se há uma figura principal no quadro de Manet é a própria pintura, a imagem como mapa. Certeau (1990, p. 202) sintetiza:

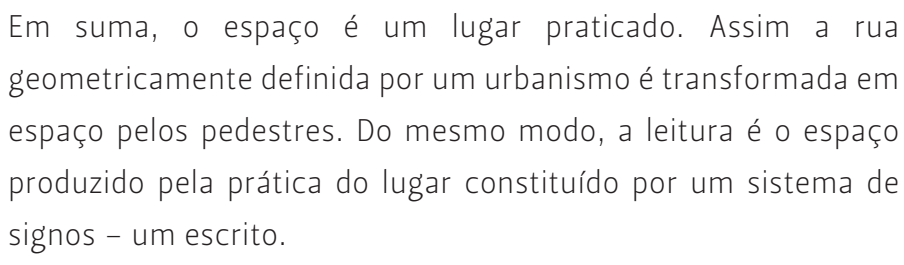

As aulas devem ser vistas pelo professor contemporâneo como um espaço de recriação constante e isto se dá através de mudanças do olhar em relação ao próprio espaço.

Saber-se criador em equipe, todos os dias, em um espaço- tempo que é a sala de aula. Mesmo se a posição dos móveis permaneça estática, dependendo da instituição na qual este professor trabalhe; a sua postura deve ser móvel e flexível, livre para expressar-se e deixar seu aluno expressar e, vez por outra, ou a todo o momento, olhar e sentir os sinais que esta imagem-situação lhe oferece: a posição dos objetos, a cor do céu, se chove, os barulhos distintos, o olhar brilhante, o olhar sem graça, a limpeza, os cheiros, o conteúdo, o vazio. Toda a trama. 
A observação do objeto de trabalho, o aluno que aprende, pode estar captando sinais que não compreendemos. Pode ser que não estejamos dispostos a sair do lugar para experimentar outro ponto de vista. Ou que precisemos também aprender. Não dá mais para fingir que dentro da sala de aula tudo é praticamente bidimensional: a folha de caderno, a tela do computador ou a ficha de estudo. Não há só altura, largura, profundidade como medidas espaciais. Há também a medida de tempo, não a do relógio, mas aquela que é calculada pela velocidade da luz. Não podemos mais abstrair tais percepções no nosso dia a dia. As descobertas científicas da Física e da Química, as invenções da telecomunicação, os estudos da Antropologia e das Ciências Sociais, a Geografia, Engenharia, Medicina, as Artes, a própria educação, nos propõem viver hábitos em nossa vida diária através do uso de novos objetos e práticas que não havíamos imaginado.

Com tantas variáveis não parece pouco oferecer aos alunos uma visão do espaço tão contida? Mas, mais do que oferecer, ao professor contemporâneo é necessário viver as possibilidades deste espaço.

Mas como? Viver o quê? Como transformar as representações arraigadas que se tem do ofício de ser professor? Baillauquès (2001, p. 40) apresenta algumas pistas:

\footnotetext{
Existe o "saber verdadeiro, o "saber comum" e o "falso saber", a recusa de conhecer e a crença nos conteúdos das representações do ofício do professor e de sua elaboração. A concepção é composta igualmente por projeções de sua experiência com determinado professor ou com vários professores que ele conheceu quando aluno. Tal concepção inclui e mantém as suas fantasias, suas construções de ideal e suas idealizações.
}

0 trabalho de formação do professor neste tempo atual deve oferecer em seus conteúdos o contato mais próximo com os seus próprios saberes, ignorâncias, hábitos e gostos. Deve dar a oportunidade ao professor para que entre em contato direto com as dúvidas que tem em relação às coisas da vida. Deve ter espaço para o exercício da imaginação e da observação. Viver experiências artísticas, de quaisquer modalidades, pode ajudar e muito o professor a transformar a relação que tem com o espaço e com o seu processo de criação, pois, conforme Salles (2006, p. 19), 
Para ilustrar e finalizar este artigo, apresento algumas imagens de trabalhos de formação realizados no Centro de Estudos Educacionais Vera Cruz (Cevec) para professores do curso de educação continuada: Fazer Perguntas, Construir Respostas em Arte, 2010.

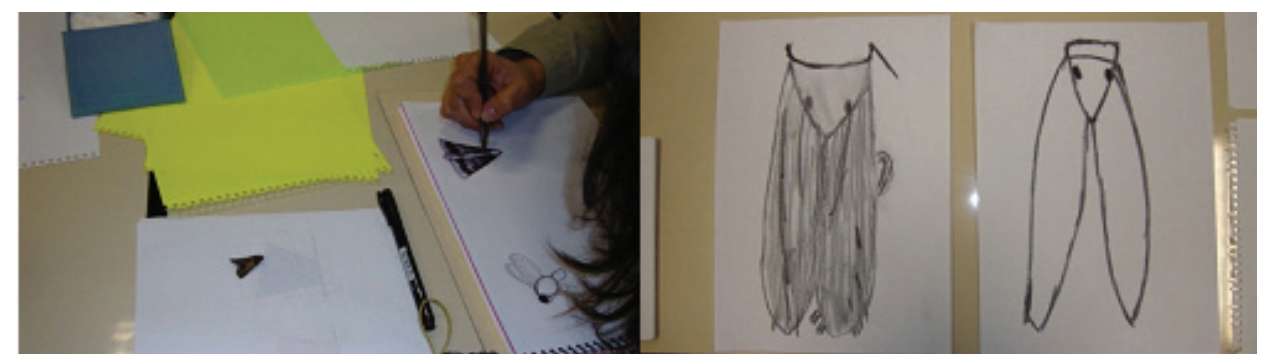

Imagem 2. Desenho de observação de insetos com carvão

As atividades que compuseram os quatorze encontros que tivemos ofereceu aos professores participantes a oportunidade de vivenciar materiais diversos dentro de um espaço e tempo próprio da arte. Ao experienciar estas atividades, o grupo e cada um individualmente, foi capaz de criar suas perguntas, tomar consciência de seus limites e lançar-se na construção de respostas e na invenção de atividades significativas para seus alunos. Construímos um grupo de confiança, em que as dúvidas e situações que causavam embaraçamento na sala de aula, em suas escolas, pudessem ali ser tratadas de uma forma respeitosa e sem medo de errar. Pudemos juntas criar situações de tirada de tapete que criaram angústias, mas ao mesmo tempo criaram soluções.

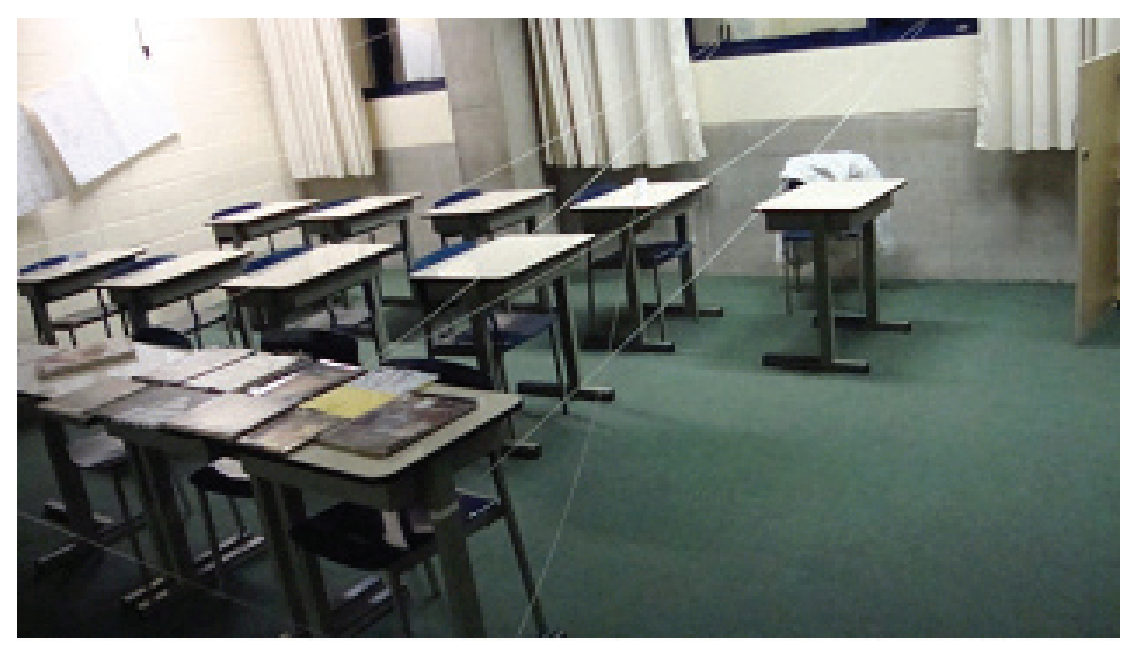

Imag'em 3. Desenho no espaço com barbante 


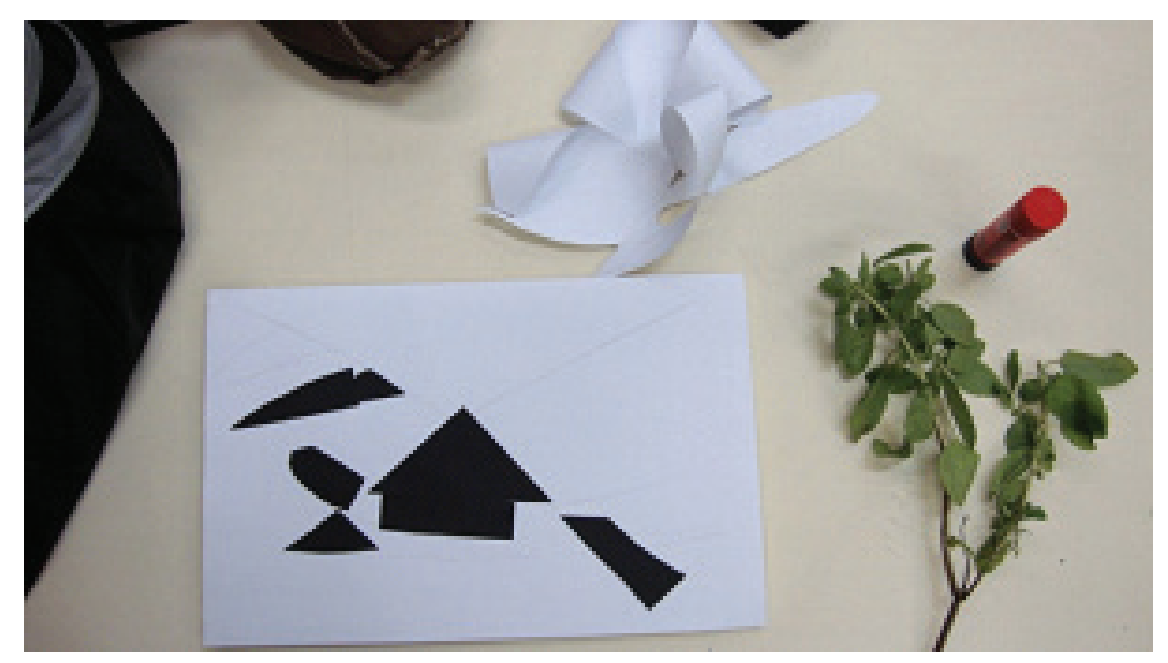

Imagem 4. Recorte e construção com papel

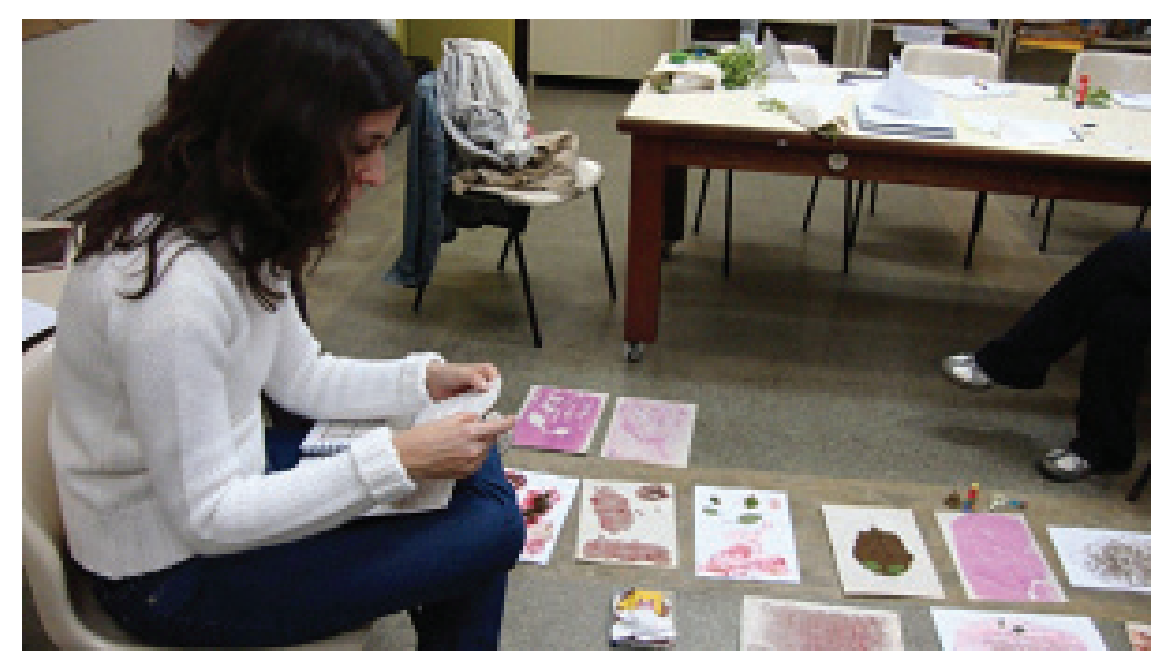

Imagem 5. Apreciação de monotipias e leitura das atividades inventadas pela professora para seus alunos

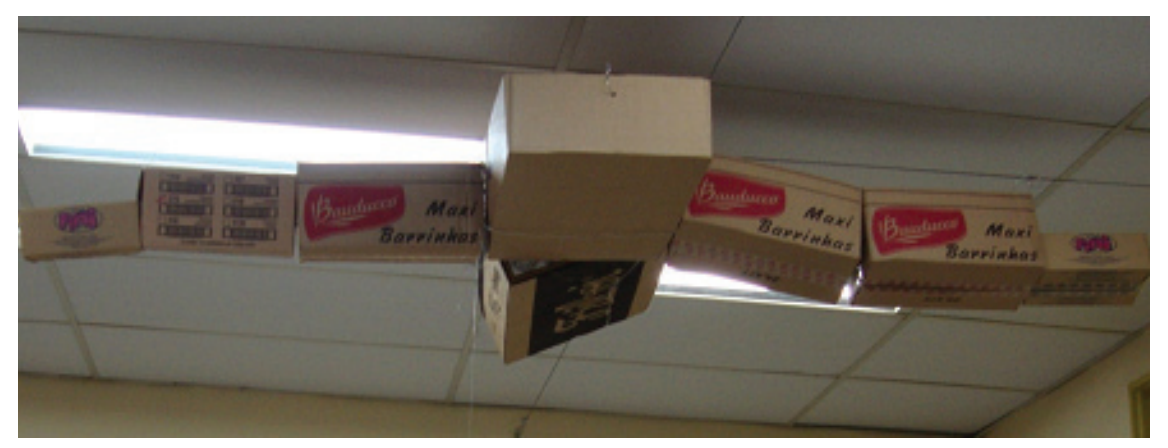

Imagem 6. Construção com material reciclável 


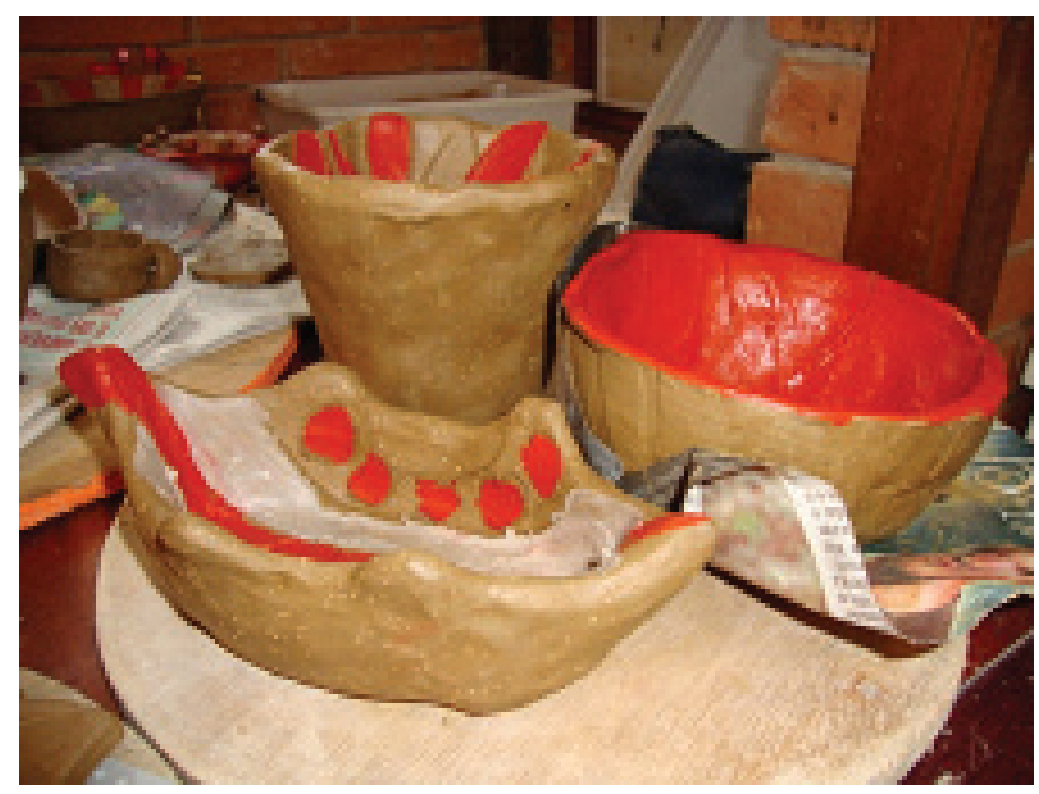

Imagem 6. Modelagem em argila

0 espaço da arte em sua flexibilidade foi capaz de acolher pessoas muito diferentes. Mostrou a elas que para transformar a ideia que se tem do espaço escolar depende só de abrir a porta e deixar a brisa nova entrar.

\section{REFERÊNCIAS}

CERTEAU, M. de. Tradução de Ephraim Ferreira Alves. A Invenção do Cotidiano: Artes de fazer. Rio de Janeiro: Vozes, 1994.

EDWARDS, C.; GANDINI, L. (Org.). Bambini: A abordagem Italiana à educação infantil. Tradução de Daniel Etcheverry Burguño. Porto Alegre: Artmed, 2002.

FLUSSER, V. Filosofia da Caixa Preta: ensaios para uma futura filosofia da fotografia. Rio de Janeiro: Relume Dumará, 2002.

IAVELBERG, R. O desenho cultivado da criança: prática e formação de educadores. Porto Alegre: Editora Zouk, 2006.

LACLOTTE, M. Tradução de Daniela Milani Xausa. Musée d'Órsay: capolavori impressionisti e post-impressionisti. Paris: Editions de La Reunion des Musées Nationaux e Thames Hudson, 1990. 
PERRENOUD, P. et al (Org.). Tradução de Fátima Murad e Eunice Gruman. Formando Professores Profissionais: Quais estratégias? Quais competências? Porto Alegre: Artmed, 2001.

SALLES, C. A. Redes da Criaçã: construção da obra de arte. São Paulo: Horizonte, 2006. 